\title{
Acolhimento e vínculo: práticas de integralidade na gestão do cuidado em saúde
} em grandes centros urbanos

Márcia Constância Pinto Aderne Gomes

Roseni Pinheiro ${ }^{2}$

GOMES, M. C. P. A; PINHEIRO, R. Reception and attachment: integral practices in health care administration in large urban centers. Interface - Comunic., Saúde, Educ., v.9, n.17, p.287-301, mar/ago 2005.

The Family Health strategy, main proposal for reorganizing the health care model, is politically, institutionally and economically supported by the State, as an alternative for the consolidation of the Unified Health System's principles. The proposal's expansion and implementation in large urban centers has faced many difficulties, due to complex social, political and economic contexts involving the families residing in these territories. These difficulties have been largely discussed by diverse Public Health specialists. This article analyses the uses and meanings of the terms "integral health care, attachment and reception", identifying them as strategic elements in health practices in integral care programs, and in constructing people's right to health as a citizenship right.

KEY WORDS: reception; attachment; integral health care; family health.

A estratégia da Saúde da Família é a principal proposta de reorganização do modelo de atenção à saúde, sendo apoiada político, institucional e economicamente pelo Estado, como alternativa de consolidação dos princípios do Sistema único de Saúde. A expansão e implementação dessa proposta, em grandes centros urbanos, tem encontrado dificuldades, tendo em vista a complexidade dos contextos sociais, políticos e econômicos que envolvem as famílias residentes nesses territórios, sendo objeto de discussão de diferentes especialistas no campo da Saúde Coletiva. Este artigo faz uma análise dos usos e sentidos atribuídos aos termos integralidade, vínculo e acolhimento, no que concerne à gestão do cuidado em saúde, identificando essas estratégias como elementos das práticas de saúde em programas de atenção integral e da construção do direito à saúde como direito de cidadania.

PALAVRAS-CHAVE: acolhimento; vínculo; atenção integral à saúde; saúde da família.

\footnotetext{
${ }^{1}$ Supervisora Operacional, Coordenação da Saúde da Comunidade, Secretaria Municipal de Saúde, Rio de Janeiro, RJ. <marconstanci@hotmail.com>

${ }^{2}$ Professora Visitante, Instituto de Medicina Social, Universidade Estadual do Rio de Janeiro; Coordenadora, Laboratório de Pesquisas sobre Práticas de Integralidade em Saúde (LAPPIS-UERJ), Rio de Janeior, RJ. <rosenisaude@uol.com.br>
}

${ }^{1}$ Rua Rosa e Silva, 60, bl. 7, apto. 208

Grajaú - Rio de Janeiro, RJ

CEP: 20541-330 


\section{Introdução}

A nova institucionalidade da saúde tem seus fundamentos no artigo 198 da Constituição Federal de 1988, que define o Sistema único de Saúde (SUS). Suas ações e serviços integram uma rede regionalizada e hierarquizada; constituem um sistema único, organizado, descentralizado, com direção única em cada esfera de governo, prestando atendimento integral, a partir da priorização de atividades preventivas (sem prejuízo das assistenciais) e com participação popular.

No início da década de 1990 foi criado o Programa de Agentes Comunitários de Saúde (PACS), pelo Ministério da Saúde. A missão do PACS era reduzir a mortalidade infantil e materna mediante oferta, às populações rurais e de periferia, de procedimentos simplificados de saúde na lógica de medicina preventiva. O objetivo era desenvolver a capacidade da população para cuidar de sua própria saúde, transmitindo informações sobre práticas preventivas, por meio de agentes comunitários (Viana \& Dal Poz, 1998, p.10).

No ano de 1994 o Ministério da Saúde criou o Programa de Saúde da Família PSF), entendido como uma proposta estruturante do Sistema de Atenção à Saúde, com objetivo de:

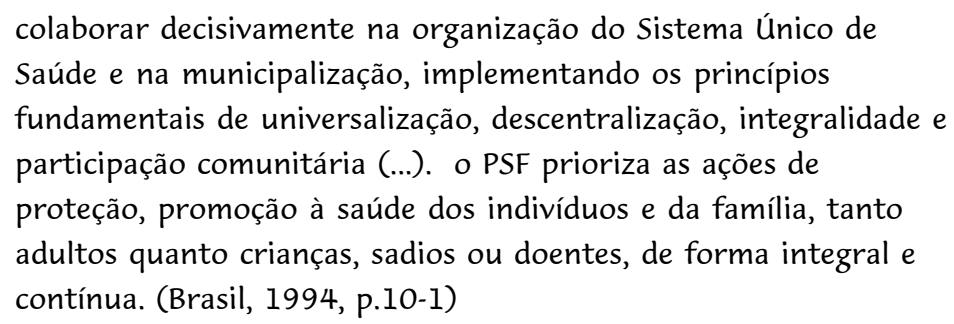

Desde sua institucionalização, o Programa de Saúde da Família vem assumindo relevância no discurso político, institucional e social no âmbito do Ministério da Saúde (Souza, 2001), com a implementação de mecanismos de alocação de recursos e outros dispositivos de financiamento. A partir de 1998, o programa é concebido pelo conjunto dos atores institucionais (em âmbito nacional, estadual e municipal) como importante norteador para o desenvolvimento de sistemas locais de saúde, ganhando status de estratégia de reorientação assistencial (Souza, 2001).

Atualmente a estratégia da Saúde da Família encontra-se em expansão em grandes centros urbanos. Existe grande expectativa de que o PSF possa vir a ser a reestruturação da atenção básica, sobretudo nas capitais brasileiras (Caetano \& Dain, 2002; Campos et al., 2002; Favoretto \& Camargo Jr., 2002; Mattos, 2002). Estes autores identificaram alguns fatores que dificultam sua implantação nas áreas metropolitanas, como por exemplo: falta de financiamento, despreparo e qualificação insuficiente dos profissionais para atuar no PSF, formato padrão/rígido para composição das equipes sem respeitar as particularidades locais, insuficiência de mecanismos de relação do PSF com outros serviços, precariedades das redes ambulatoriais e hospitalares, dinâmica urbana complexa, violência urbana, tráfico de drogas e armas e dificuldade da interação de novos saberes e de novas 
práticas para ações coletivas e sociais no âmbito do PSF.

Um dos principais motivos para o PSF apresentar transformações positivas e significativas na reorganização da atenção básica, segundo Pinheiro (2001), está no fato de o programa buscar, em seus objetivos e suas metas institucionais, políticas e sociais, a centralidade de suas ações na integralidade da atenção e do cuidado à família. Para tanto, privilegiou-se a equipe de profissionais como importante elemento para a materialização dessas metas e objetivos, para os quais foram criados mecanismos de fomento $e$ incentivo à realização de atividades voltadas para formação, capacitação e remuneração dos integrantes da equipe. Tais atividades consistem em propiciar condições favoráveis ao estabelecimento de um novo patamar de relação entre profissionais, gestores e famílias, de modo a garantir o princípio da integralidade (Pinheiro, 2001). Nesse sentido, "a integralidade pode ser entendida como uma ação resultante da interação democrática entre atores no cotidiano de suas práticas na oferta do cuidado de saúde, nos diferentes níveis de atenção do sistema" (Pinheiro, 2002, p.15).

Não se quer negar, com isso, a existência de obstáculos concretos na construção do SUS, sobretudo os desafios para garantir a integralidade como direito a serviços no sistema de saúde brasileiro. Porém, vêm sendo identificados avanços importantes na reorganização de serviços que apontam o acolhimento e o vínculo (Teixeira, 2003; Lopez et al., 2002; Malta, 2001; Franco et al., 1999; Merhy, 1997) como diretrizes operacionais para a materialização dos princípios do SUS - em particular a integralidade, universalização e eqüidade em saúde (Brasil, 2002; Pinheiro, 2002; Cecílio, 2001).

Considerando o exposto, este artigo busca analisar os usos e sentidos atribuídos aos termos integralidade, vínculo e acolhimento, identificando essas estratégias como elementos das práticas de saúde em programas de atenção integral em grandes centros urbanos.

\section{Atenção e cuidado em saúde: integralidade - acolhimento - vínculo}

Partimos do pressuposto de que existem vários sentidos atribuídos para a integralidade, e partilhamos da idéia de Mattos (2001) de que esse princípio do SUS, definido no texto constitucional, deva constituir uma bandeira de luta, repleta de valores que devem ser defendidos, e cujo conceito continua em construção.

Todavia, torna-se necessário sistematizar os conhecimentos que se associam a esse entendimento, tomando como guia o ensaio desse autor, que reúne três conjuntos de sentidos sobre a integralidade: a integralidade como traço da boa medicina, a integralidade como modo de organizar as práticas $e$ a integralidade como respostas governamentais a problemas específicos de saúde.

No primeiro conjunto de sentidos, a integralidade, um valor a ser sustentado, um traço de uma boa medicina, consistiria em uma resposta ao sofrimento do paciente que procura o serviço de saúde, e um cuidado para que ela não seja a redução ao aparelho ou sistema biológico deste, pois tal 
redução cria silenciamentos. A integralidade está presente no encontro, na conversa, na atitude do médico que busca prudentemente reconhecer, para além das demandas explícitas, as necessidades dos cidadãos no que diz respeito à sua saúde. A integralidade está presente também na preocupação desse profissional com o uso das técnicas de prevenção, tentando não expandir o consumo de bens e serviços de saúde, nem dirigir a regulação dos corpos.

No segundo conjunto de sentidos, a integralidade, como modo de organizar as práticas, exigiria uma certa "horizontalização" dos programas anteriormente verticais, desenhados pelo Ministério da Saúde, superando a fragmentação das atividades no interior das unidades de saúde. A necessidade de articulação entre uma demanda programada e uma demanda espontânea aproveita as oportunidades geradas por esta para a aplicação de protocolos de diagnóstico e identificação de situações de risco para a saúde, assim como o desenvolvimento de conjuntos de atividades coletivas junto à comunidade.

Por último, há o conjunto de sentidos sobre a integralidade e as políticas especialmente desenhadas para dar respostas a um determinado problema de saúde ou aos problemas de saúde que afligem certo grupo populacional. A Política Nacional de Aids é a que mais se aproxima do princípio, pois apresenta perspectivas preventivas e assistenciais, respeitando os direitos dos que vivem com a doença e assumindo a responsabilidade de distribuir gratuitamente os anti-retrovirais.

Em que pese a concordância de que a integralidade continua sendo um conceito em construção, realizamos um exercício teórico de formulação de uma definição operatória de integralidade como modo de atuar democrático, do saber fazer integrado, em um cuidar que é mais alicerçado numa relação de compromisso ético-político, de sinceridade, responsabilidade e confiança (Pinheiro \& Mattos, 2001, 2003; Merhy, 1997). Entende-se o sujeito como ser real, que produz sua história e é responsável pelo seu devir (Ayres, 2001). Respeita-se os saberes das pessoas (saber particular e diferenciado), saberes históricos que foram silenciados e desqualificados (Foucault, 1999), e que, neste estudo, representam uma atitude de respeito que possa expressar compromisso ético nas relações gestores/profissionais/usuários.

Desta forma, integralidade existe em ato e pode ser demandada na organização de serviços e renovação das práticas de saúde, sendo reconhecida nas práticas que valorizam o cuidado e que têm em suas concepções a idéiaforça de considerar o usuário como sujeito a ser atendido e respeitado em suas demandas e necessidades (Pinheiro, 2001).

Sua visibilidade se traduz na resolubilidade da equipe e dos serviços, por meio de discussões permanentes, capacitação da equipe, utilização de protocolos e na reorganização dos serviços. Como exemplo, tem-se o acolhimento/usuário-centrado (Franco et al., 1999) e a democratização da gestão do cuidado pela participação dos usuários nas decisões sobre a saúde que se deseja obter (Pinheiro, 2003).

Isto posto, podemos reconhecer, nas estratégias de melhoria de acesso e desenvolvimento de práticas integrais, o acolhimento, o vínculo e a responsabilização como práticas integrais (Pinheiro, 2002). O acolhimento, enquanto diretriz operacional, propõe inverter a lógica da organização e do funcionamento do serviço de saúde (Franco et al., 1999), e que este seja 
${ }^{3}$ Solidariedade em Sociologia: Durkheim (1893) distinguiu a solidariedade mecânica de solidariedade orgânica. A mecânica é própria de uma sociedade onde os papéis são pouco diferenciados. A solidariedade orgânica é própria de papéis muito diferenciados, nos quais a

complementaridade de cada um em relação ao outro exige colaboração ativa. Acreditamos que o texto fala de solidariedade orgânica. organizado de forma usuário-centrado. Para tal fim, os autores partem dos seguintes princípios:

\footnotetext{
1 Atender a todas as pessoas que procuram os serviços de saúde, garantindo a acessibilidade universal. Assim, o serviço de saúde assume sua função precípua, a de acolher, escutar e dar uma resposta positiva, capaz de resolver os problemas de saúde da população.

2 Reorganizar o processo de trabalho, a fim de que este desloque seu eixo central, do médico para uma equipe multiprofissional equipe de acolhimento -, que se encarrega da escuta do usuário, comprometendo-se a resolver seu problema de saúde.

3 Qualificar a relação trabalhador-usuário, que deve dar-se por parâmetros humanitários, de solidariedade ${ }^{3}$ e cidadania.

(Franco et al.., 1999, p.347)
}

Os mesmos autores defendem o acolhimento como dispositivo para interrogar processos intercessores que constroem relações nas práticas de saúde, buscando a produção da responsabilização clínica e sanitária e a intervenção resolutiva, reconhecendo que, sem acolher e vincular, não há produção dessa responsabilização (Franco et al., 1999).

Merhy (1994) propõe refletir como têm sido nossas práticas nos diferentes momentos de relação com os usuários. O autor afirma que uma das traduções de acolhimento é a relação humanizada, acolhedora, que os trabalhadores e o serviço, como um todo, têm de estabelecer com os diferentes tipos de usuários.

Em nossa busca prévia pelos conceitos atribuídos aos termos acolhimento e vínculo, recorremos a alguns dicionários de língua portuguesa, a fim de verificar concordância, além de observar o nexo lexical.

No Dicionário Aurélio de Língua Portuguesa, o termo acolhimento está relacionado ao "ato ou efeito de acolher; recepção, atenção, consideração, refúgio, abrigo, agasalho". E acolher significa: dar acolhida ou agasalho a; hospedar; receber: atender; dar crédito a; dar ouvidos a; admitir, aceitar; tomar em consideração; atender a". Já vínculo é "tudo o que ata, liga ou aperta; ligação moral; gravame, ônus, restrições; relação, subordinação; nexo, sentido".

No Dicionário Houaiss, o termo acolhimento não existe, porém acolher significa "oferecer ou obter refúgio, proteção ou conforto físico. Ter ou receber (alguém) junto a si. Receber, admitir, aceitar. Dar crédito, levar em consideração". Já vínculo é definido como "aquilo que ata, liga ou aperta: que estabelece um relacionamento lógico ou de dependência, que impõe uma restrição ou condição".

É interessante notar que os sentidos atribuídos às palavras não se correlacionam diretamente às questões de saúde, mas podemos identificar alguns de seus significados, como: "atenção, consideração, abrigo, receber, atender, dar crédito $a$, dar ouvidos a, admitir, aceitar, tomar em consideração, oferecer refúgio, proteção ou conforto físico, ter ou receber alguém junto a si", atributos de atenção 
integral à saúde, enfim, da integralidade (grifos nossos).

Acreditamos que os valores implícitos nessas palavras nos permitem realizar diferentes aproximações com as distintas produções sobre o tema, em particular com os documentos institucionais, como aqueles produzidos pelo Ministério da Saúde que descrevem os objetivos do PSF e destacamos: a definição de responsabilidades entre serviços e população, a Humanização das práticas da saúde, o estabelecimento de um vínculo entre profissionais de saúde e a população, o estímulo à organização da comunidade para o exercício do controle social e o reconhecimento da saúde como direito de cidadania (Brasil, 1997) (grifos nossos).

Reconhecemos que existe uma vasta produção acerca da categoria vínculo no âmbito da psicologia social (psicologia social e comunitária), porém, optamos por uma releitura no campo da política e gestão, na qual verifica-se escassez quanto ao protagonismo dos gestores na responsabilização da interação entre os sujeitos na organização das práticas de cuidado. Assim, para melhor entender os nexos constituintes entre as idéias sobre vínculo no contexto da saúde, recorremos às contribuições de Victora et al. (2000), segundo as quais o estudo do conjunto específico de vínculos entre um conjunto específico de pessoas pode ser usado para interpretar o comportamento social das pessoas envolvidas. A esse conjunto dá-se o nome de rede de relações sociais. O entendimento de como elas se organizam, como os intercâmbios são realizados e as formas de troca socialmente aceitáveis são importantes para a compreensão da estrutura social na qual as redes se realizam.

As autoras afirmam que, para o estudo da rede de relações, é importante observar:

a) o que é trocado, isto é, o conteúdo dos vínculos (bens materiais, drogas, favores sexuais, relações de amizade, cumplicidade, hostilidade);

b) com quem é trocado, ou seja, se são relações horizontais que se dão dentro de uma mesma geração ou entre pessoas com o mesmo status do grupo, ou são relações verticais do tipo patrão e empregado, entre pais e filhos;

c) o quanto é trocado, isto é, a densidade dos vínculos, se estreitos ou fluidos, contínuos ou eventuais.

A ausência de ruptura entre quem oferece ou presta serviço e quem o recebe, a tendência constante para diminuir o fosso, personalizar a relação é o que caracteriza o vínculo comunitário, segundo Godbout (1999, p.89) ${ }^{4}$. O autor enfatiza "o fato de que o princípio e o motor da ação têm origem no vínculo existente entre os membros da organização ou entre a associação da pessoa ajudada, a qual, aliás, muito raramente é chamada de 'cliente"'.

Talvez essa afirmação nos ajude a compreender a aposta bem-sucedida de ter o agente comunitário de saúde como promotor do elo, portanto o vínculo entre o PSF e a comunidade, justamente por ser morador do mesmo local das famílias, fazendo parte de uma rede de relações, com atributos de solidariedade e liderança e conhecimento da realidade social - requisitos para sua seleção (Brasil, 1997, 2000).

Essa iniciativa talvez diminua os efeitos da assertiva de Godbout (1999) à
${ }^{4}$ Em O espírito da dádiva, o autor mostra que toda a sociedade vive da dádiva $e$ necessita dessa "graça" para manter a vida em suas redes. Demonstra que Papai Noel, alcoólicos anônimos, doações de órgãos e de sangue, serviços prestados e outros têm a dádiva em comum. Demarca posição, não tolerando que todas as coisas e todos os serviços se produzam de forma automática, impessoal, e que eles podem se manifestar fora das leis do mercado e das regras do Estado. 
substituição de vínculos comunitários, assumidos por relações de parentesco, vizinhança e amizade (vínculos diretos) por um conjunto de "serviços" transferidos a "empregados" do setor público ou organismos especializados nesses serviços e subsidiados pelo Estado. Ele afirma que esta "liberação" do vínculo comunitário estaria transformando a democracia em um mecanismo quase mercantil, pois estaríamos pagando com nossos impostos, a indivíduos que seriam pagos para cumprir o 'trabalho social'.

Silva et al. (2004) utilizaram figuras de linguagem - metáforas (elo, laço e nó) - para simbolizar as maneiras como o agente comunitário de saúde se coloca diante de seus saberes e de suas práticas, na pesquisa em que foi explorada a tradução e o estabelecimento de processos comunicativos entre equipe de saúde e comunidade como tarefa primordial do agente comunitário $e$ identificaram que:

\author{
Esta tradução pode fazer desse sujeito elo ou laço . Elo na medida \\ em que serve apenas como veículo de informações; laço, quando \\ consegue estabelecer um território comum onde os sujeitos e seus \\ saberes interagem e dialogam, gerando ações comuns que sustenta a \\ existência desse espaço de encontros. \\ ... há momentos em que o agente comunitário se encontra tão preso \\ em sua própria corrente, que os elos se enroscam conformando um \\ nó. Isso pode ser percebido através de sua formação para o trabalho, \\ gerando entraves no fluxo de interações entre equipe de saúde e \\ comunidade. (Silva et al., 2004, p.88-9)
}

Por outro lado, Coutinho (1999a) ressalta Gramsci em sua discussão sobre democracia, que não se converte em cultura política se não é partilhada intersubjetivamente pelos cidadãos, não se configurando como valor universal e realidade prática. Sendo assim, a equipe de PSF pode desempenhar papel estratégico na democracia, pois estaria a serviço de um sistema democrático global, com programas voltados para os interesses mais gerais da comunidade (Rouanet, 2003).

A noção de vínculo nos faz refletir sobre a responsabilidade e o compromisso (Merhy, 1994). Assim sendo, ela está em consonância com um dos sentidos de integralidade. Afirma o autor:

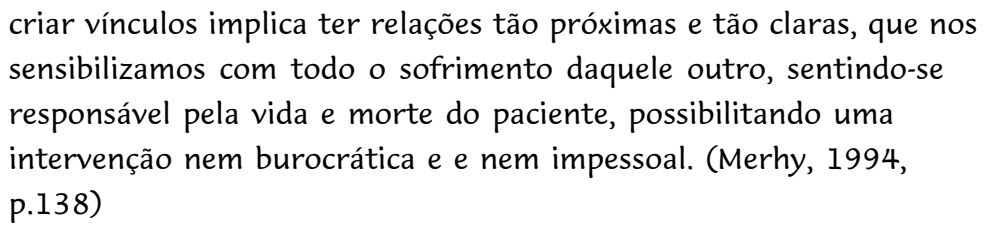

Esta definição apresenta interseções com os sentidos atribuídos por Mattos (2001), que se fazem reconhecidamente inovadores enquanto dispositivos institucionais no cotidiano das práticas estudadas por Pinheiro (2002).

Tal definição encontra consonância com o relatório da $10^{\mathrm{a}} \mathrm{CNS}$ e com os documentos do Ministério da Saúde que tratam de vínculo. Poderíamos dizer que as diretrizes operacionais do PSF orientam para novo tipo de cuidado $e$ 
direcionam para que haja responsabilização e compromisso no ato do vínculo, e que esse desejo é compartilhado pela Sociedade Civil5.

\section{Saúde da Família em grandes centros urbanos: poder - democracia - cidadania}

A estratégia de expansão de cuidados básicos de saúde está voltada a grupos populacionais sob maior risco social e expostos a precárias condições sanitárias, e que carrega em seu bojo a expectativa de transformação do modelo assistencial (Caetano \& Dain, 2002). Em 2000, respondia apenas por um terço dos habitantes do país, em função de sua implantação predominante em municípios de pequeno porte, enquanto aqueles de maior população tiveram pouca adesão. Com o propósito de mudar essa situação, foi desenvolvido um projeto para o investimento nas grandes cidades $e$ centros urbanos com o objetivo de estimular a implantação da Estratégia nesses cenários. O Projeto de Expansão e Consolidação da Saúde da Família PROESF é uma iniciativa do Ministério da Saúde, apoiada pelo Banco Mundial - BIRD, voltada para o fortalecimento da atenção básica no país. O Projeto está estruturado em três componentes de atuação:

1 Apoio à conversão e expansão da estratégia Saúde da Família

2 Desenvolvimento de recursos humanos da estratégia Saúde da Família

3 Monitoramento e avaliação

Porém, esse atraso na implantação pode ser interpretado de várias formas (financiamento, organização de serviços, decisão política e outras), e uma delas é a enorme diversidade demográfica do país, além de outras não menos relevantes.

Grande parte da população brasileira vive em situação de pobreza e de extrema pobreza, em contraste com a relativa riqueza do país. Essa desigualdade expressa-se mais claramente em centros urbanos, principalmente nas favelas.

A favela existe no cenário carioca desde o século XIX e sempre foi representada como uma cidade à parte, que muitos pretenderam eliminar, controlar ou esquecer (Alvito, 2001). No início do século XX, o nome próprio Favella passou a ser favela, servindo para denominar os casos de terra invadida ou ocupada ilegalmente por moradias precárias e população pobre. O "tipo ideal" se construiu a partir do Morro da Providência e do Morro de Santo Antônio, onde se foram associando esses espaços às ocupações ilegais situadas na encosta do morro com moradias precárias, sem infra-estrutura e serviços urbanos. $O$ favelado passou a simbolizar $o$ migrante pobre, semi-analfabeto, biscateiro, incapaz de se integrar e se adaptar ao mercado de trabalho da cidade (Preteceille \& Valladares, 2000).

Segundo Alvito (2001), as favelas representaram os fantasmas prediletos do imaginário urbano: foco de doenças e epidemias; sítio de malandros e ociosos, inimigos do trabalho duro e honesto; amontoado promíscuo de população sem moral; reduto anacrônico de migrantes de origem rural maladaptados à vida urbana, constituindo uma massa ignara a atrasar nosso desenvolvimento econômico e político; e covil de bandidos, zona franca do crime e do tráfico. Assim, a favela tem em si encarnada a imagem das
${ }^{5} \mathrm{Na}$ visão de Gramsci,

"sociedade civil é uma arena privilegiada da

luta da classe, uma

esfera do ser social

onde se dá uma

intensa luta pela

hegemonia; $e$,

precisamente por isso,

ela não é o 'outro' do

Estado, mas

juntamente com a

'sociedade política' ou

o 'Estado-coerção' -

um dos seus

inelimináveis

momentos

constituitivos"

(Coutinho, 1999b). 
${ }^{6}$ Classes perigosas:

Termo surgido na época da revolução industrial, onde associava-se a pobreza com delinqüência As classes delinqüentes existiam dentro de fronteiras geográficas e sociais claramente identificáveis: viviam em uma determinada área de Londres, em um só bairro, identificados pelo meio ambiente, sua linguagem. suas roupas e seus comportamentos particulares. As classes perigosas inglesas tinham atividades ilícitas e sua moral e costumes não eram convencionais, dedicando seus delitos contra a propriedade e a pessoas de diversos graus (Himmelfarb, 1988). "classes perigosas", e é esta tradição que é continuadamente reproduzida (Alvito, 2001, p.91-2).

Oliveira (1999) ressalta que vários trabalhos vão contra a associação equivocada entre pobreza e violência urbana e criminalidade; porém a favela apresenta interfaces entre múltiplos arranjos culturais de mundos (o marginal e o central, o desviante e o oficial), que se interpenetram. $\mathrm{O}$ mundo do crime não está muito distante do mundo empresarial, muito menos do mercado, seus valores e regras. Eles participam simultaneamente das exigências do mundo do trabalho e do crime, realizando diversos tipos de acordo e compromisso.

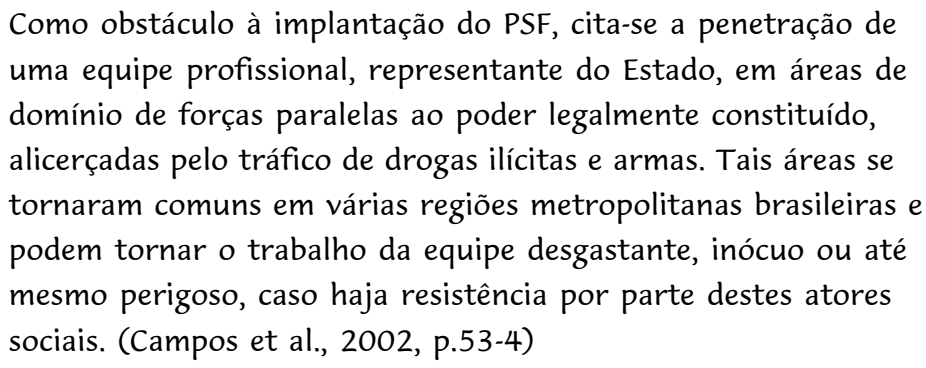

Embora se compreenda a importância do impacto da violência sobre as populações assistidas pelo PSF, não é objetivo deste trabalho discuti-la. No entanto, é importante ressaltar que é nessa "ginástica de conciliação entre pressões de moradores, poder público, polícia, banditismo, medo e tensões, conflitos, regras de convivência forçada, acordos tácitos e compromissos" (Oliveira, 1999, p.68), cenário incompatível com cidadania e democracia, que a equipe de saúde da família inicia seu trabalho.

A proposta de construção desse novo modelo assistencial é parte indissociável da consolidação e aprimoramento do Sistema único de Saúde, cujos objetivos também são:

- Contribuir para a democratização do conhecimento do processo saúde / doença, da organização dos serviços e da produção social da saúde.

- Fazer com que a saúde seja reconhecida como um direito de cidadania e, portanto, expressão de qualidade de vida.

- Estimular a organização da comunidade para o efetivo exercício do controle social” (Brasil, 1997, p.10) (grifos nossos)

Isto demonstra que o desempenho do processo de trabalho do PSF deve estar relacionado à existência de profissionais que têm claro em suas mentes o papel de agente transformador, assegurando a participação e o controle social, tornando transparentes as informações, criando vínculos efetivos entre usuários e equipe e estabelecendo relações de trocas e confiança.

O conceito de transformação social aqui proposto é o de Gramsci, segundo o qual a transformação (revolução) é concebida como um processo de construção de uma nova hegemonia (processo de articulação de diferentes interesses em torno de um projeto de transformação). 
De acordo com Dagnino (2000), isto implicaria uma nova concepção de mundo, em que o papel das idéias e da cultura assume caráter positivo, tendo sua base construída a partir de duas formulações principais: a noção de poder e a construção histórica da transformação social. Neste sentido, implantar o PSF em uma comunidade, com esses propósitos, significa rever também as relações de poder existentes nas instituições de saúde entre profissionais, usuários e gestores.

Acreditamos que analisar as transformações da prática inclui, necessariamente, o exame dessas relações. Afinal, os espaços institucionais (e o PSF não seria diferente), são loci de poderes, interesses e projetos de diferentes sujeitos (Pinheiro, 2001).

Para Foucault (1999), a análise do poder é uma análise das relações, porque os sujeitos se relacionam com outros sujeitos segundo suas necessidades e possibilidades. Isto leva a uma reflexão sobre as práticas de PSF. Se repetirmos o modelo vigente apenas maquiado, acreditando que, atendendo a família, fazendo visita domiciliar, prestando assistência, promovendo as ações de prevenção e promoção de saúde sem respeitar o desejo/projeto de vida do paciente, sem colocá-lo para discutir isto e as práticas de serviço, estaremos apenas mantendo as relações de poder de dominação. Ou seja:

as relações de poder têm uma relação de força estabelecida em dado momento e que se reinsere perpetuadamente numa espécie de guerra silenciosa nas desigualdades econômicas, na linguagem, nos corpos de uns e outros. (Foucault, 1999, p.21)

Se "o poder não se dá, nem se troca, nem se retoma, mas (...) se exerce e só existe em ato" (Foucault, 1999, p.21), qual o verdadeiro poder exercido e que existe em ato nas práticas cotidianas do PSF? Como essas práticas podem existir enquanto estratégia de inserção social e democratização da população?

Acreditamos que "contribuir para a democratização do conhecimento do processo saúde / doença, da organização dos serviços e da produção social da saúde, estimular a organização da comunidade para o efetivo exercício do controle social" (Brasil, 1997, p.10) significa redistribuir o poder (grifos nossos).

\footnotetext{
Da perspectiva do processo de construção da cidadania e do espírito democrático entre nós, parece ser o momento de fazer avançar esse processo nos espaços micropolíticos, como são os espaços dos serviços, contribuindo para que a essência de suas práticas seja a realização da democracia viva em ato. (Teixeira, 2003, p.95)
}

Para o autor, a superação do monopólio do diagnóstico de necessidades e de se integrar a "voz do outro" é mais que a construção de um vínculo/ responsabilização. É uma efetiva mudança na relação de poder técnicousuário, evidenciando, segundo Gramsci, "as possibilidades que tem o ser 
social de passar do reino da necessidade para o reino da liberdade" (Simionatto, 1998, p.45).

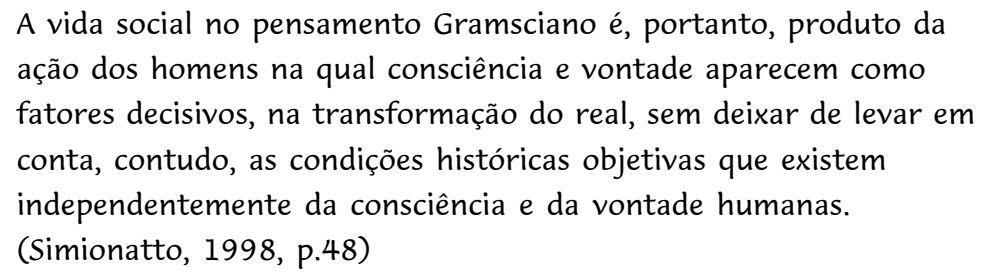

Neste contexto reaparecem os saberes sujeitados. É na insurreição dos saberes antes desqualificados, não legitimados, contrários à instância teórica unitária que pretenderia filtrá-los, hierarquizá-los ou ordená-los em nome de um conhecimento verdadeiro (Foucault, 1999), que surgem os sujeitos sociais.

Assim, a dimensão da cultura é crucial. Ela requer uma reforma intelectual $e$ moral: nela a constituição de sujeitos é privilegiada, pois os elementos como vontade, paixão e fé receberam em Gramsci mais importância do que a dinâmica das estruturas sociais objetivas. É no terreno da cultura que o consentimento ativo definidor de hegemonia e distinto de dominação é produzido, ou não (Dagnino, 2000).

Dagnino (2000) recorre a Gramsci e afirma que a hegemonia é um processo de articulação de diferentes interesses para se construir "uma vontade coletiva", sendo um processo de formação de sujeitos, no qual a capacidade de "transcender interesses corporativos e particulares, de fazer compromissos e negociar são características fundamentais" nessa construção em processo, uma articulação sempre submetida à reelaboração e renovação como ação política na direção da transformação social (p.73).

Parece-nos que a existência de obstáculos e desafios na construção do SuS não inviabiliza as possibilidades da estratégia do PSF de provocar transformações significativas na reorganização das práticas, a partir da mudança do objeto de atuação para a família e o resgate das ações de prevenção e promoção, além da busca de satisfação do usuário (Brasil, 2000). Isto implica reconhecer a relevância desse tipo de estratégia na construção do direito à saúde como uma questão de cidadania. Neste sentido, é necessário rever o papel da equipe, dos gestores e usuários na ampliação dos espaços de participação popular, refletindo sobre suas relações de poder. Cidadania caminha ao lado da democracia, e democracia se faz em ato.

Segundo Bobbio (2002), os direitos de cidadania são históricos $e$ legitimados por lutas em defesa da liberdade e contra velhos poderes, e se deram de maneira gradual. Primeiramente, afirmaram-se os direitos civis de liberdade, que tendem a limitar o poder do Estado, reservando-o para indivíduos ou grupos particulares. Num segundo momento, são promulgados os direitos políticos como forma de autonomia em relação ao Estado e finalmente os direitos sociais, que vêm como expressão do amadurecimento de novas exigências, como bem-estar e igualdade definidos por meio do Estado.

Assim sendo, a cidadania é um conceito em construção e possui sentidos $e$ significados coerentes com o seu tempo. A nova cidadania tem como referente central a noção de direitos. $\mathrm{O}$ direito a ter direitos. $\mathrm{O}$ direito à igualdade $e$ à 
diferença. A reivindicação ao acesso, à inclusão, participação $e$ ao pertencimento a um sistema político já dado. As origens da atual redefinição podem ser parcialmente encontradas nas experiências de movimentos sociais no final da década de 1970 e nos anos 1980, tendo o termo se difundido a partir do início dos anos 1990 pela sociedade brasileira. A nova cidadania busca implementar a construção democrática, de transformação social, que impõe laço constitutivo entre cultura e política (Dagnino, 2000).

\section{Conclusão}

O Programa de Saúde da Família é uma estratégia do Ministério da Saúde que propõe ações de promoção, proteção e recuperação da saúde dos indivíduos, a partir da efetivação de suas diretrizes operacionais. A primeira possibilidade de efetivação dessas ações pode estar localizada no momento do acolhimento. O confronto entre as necessidades de saúde (ou outras) trazidas pelos usuários e o que a instituição, no caso o PSF, tem a oferecer, poderá revelar as mudanças no modelo assistencial.

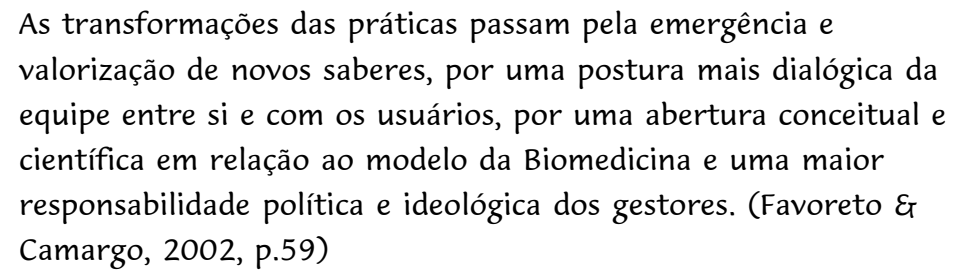

Essas transformações são potenciais construtoras de vínculo, aproximando quem oferece ou presta serviço de quem o recebe e personalizando a relação, que deve ser compromissada, solidária e aparecer como "fruto de uma construção social e parte de um esforço que envolve equipe, instituições e comunidade" (Silva et al., 2004, p.79).

De acordo com Gramsci, a capacidade de transcender interesses corporativos e particulares, de fazer compromissos e negociar, são características hegemônicas fundamentais, na medida em que tornam possível a articulação de diferentes. A implantação de PSF é um grande desafio para os profissionais idealistas, para a população que vem buscando seus direitos e para o gestores que precisam romper com práticas instituídas nos serviços. Contribuir para a democratização do conhecimento, fazer a saúde ser reconhecida como um direito de cidadania e estimular a organização da comunidade para o efetivo exercício do controle social significam redistribuir os poderes, $e$ isto não parece ser tarefa fácil. O maior desafio dos profissionais da estratégia da saúde da família é concretizar, na prática cotidiana, a superação do monopólio do diagnóstico de necessidades $e$ de se integrar à "voz do outro", que é mais que a construção de um vínculo/responsabilização. Traduzindo-se em uma efetiva mudança na relação de poder técnico-usuário, evidenciando o ser social, com vida plena $e$ digna como expressão de seu direito. A integralidade da atenção à saúde, em suas ações de promoção, prevenção e assistência poderá, assim, representar um novo modo de "andar na vida", numa perspectiva que coloca o usuário como sujeito de sua própria história. 


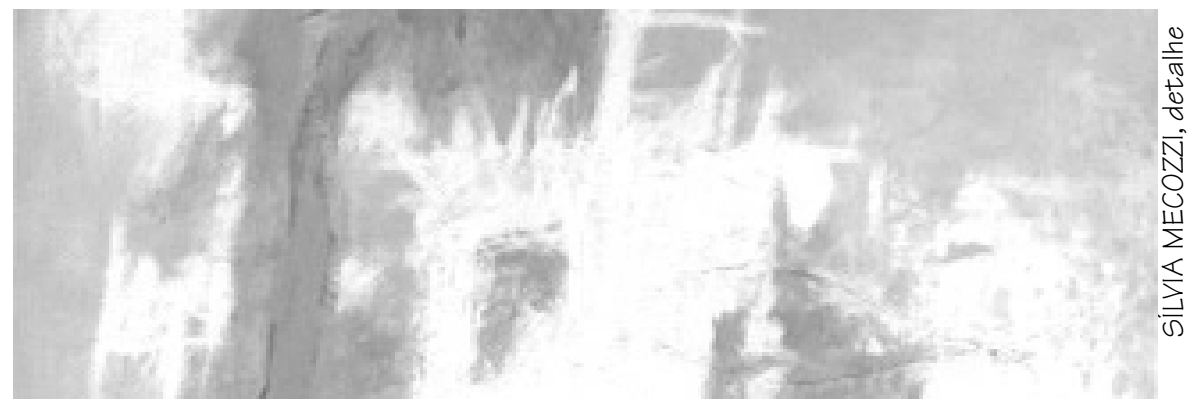

\section{Referências}

ALVITO, M. As cores de Acari: uma favela carioca. Rio de Janeiro: FGV Editora, 2001.

AYRES, J.R.C.M. Sujeito, intersubjetividade e práticas de saúde. Cadernos de Saúde Pública, v.1, n.1, p.63-72, 2001.

BOBBIO, N.; MATTEUCCI, N.; PASQUINO, G. Dicionário de política. Brasília: UnB, 2002. v.1-2.

BRASIL. Ministério da Saúde. Experiências Inovadoras no SUS: relatos de experiências.

Desenvolvimento de novas tecnologias assistenciais de atenção aos usuários. Secretarias Estaduais e Municipais de Saúde. Brasília, 2002.

BRASIL. Ministério da Saúde. A implantação da Unidade de Saúde da Família. Brasília: Secretaria de Políticas de Saúde/Departamento de Atenção Básica, 2000.

BRASIL. Ministério da Saúde. Saúde da Família: uma estratégia para a reorientação do modelo assistencial. Brasília, 1997.

BRASIL. MINISTÉRIO DA SAÚDE. Programa de saúde da família: saúde dentro de casa. Brasília: Ministério da Saúde, 1994.

CAETANO, R.; DAIN, S. O Programa de Saúde da Família e a reestruturação da atenção básica à saúde nos grandes centros urbanos: velhos problemas, novos desafios. Physis, v.12, n.1, p.11-21, 2002.

CAMPOS, F.E.C.; AGUIAR, R.A.T.; OLIVEIRA, V.B. O desafio da expansão do Programa de Saúde da Família nas grandes capitais brasileiras. Physis, v.12, n.1, p.47-58, 2002.

CECÍLIO, L. C. O. As necessidades de saúde como conceito estruturante na luta pela integralidade e eqüidade na atenção em saúde. In: PINHEIRO, R., MATTOS, R. A. (Orgs.) Os sentidos da integralidade na atenção e no cuidado de saúde. Rio de Janeiro: IMS-UERJ/Abrasco, 2001. p.113-126.

COUTINHO, C.N. Observações metodológicas sobre os Cadernos do Cárcere. In: COUTINHO, C.N. (Org.) Gramsci: um estudo sobre seu pensamento político. Rio de Janeiro: Civilização Brasileira, 1999a. p.75-118.

COUTINHO, C.N. Prefácio. In: GIOVANNI, S. Gramsci e a sociedade civil. Petrópolis: Vozes, 1999b.

DAGNINO, E. Cultura, cidadania e democracia. A transformação dos discursos e práticas na esquerda latino-americana. In: ALVAREZ, S.; DAGNINO, E.; ESCOBAR, A. (Orgs.) Cultura e política nos movimentos sociais latino-americanos. Belo Horizonte: Novas Leituras, 2000. p.61-102.

DURKHEIM, D. E. De la division du travail social. 7.ed. Paris: PUF, 1960.

FAVORETO, C.A.O.; CAMARGO JR., K.R. Alguns desafios conceituais e técnico-operacionais para o desenvolvimento do programa de saúde da família como uma proposta transformadora do Modelo Assistencial. Physis, v.12, n.1, p.59-76, 2002. 
GOMES, M. C. P. A; PINHEIRO, R.

FOUCAULT, M. Aula de 7 de janeiro de 1976. In: FOUCAULT, M. Em defesa da sociedade. São Paulo: Martins Fontes, 1999. p.3-26.

FRANCO, T.B.; BUENO, W.S.; MERHY, E.E. O acolhimento e os processos de trabalho em saúde: Betim, Minas Gerais, Brasil. Cad. Saúde Pública, v.2, n.15, p.345-53, 1999.

GODBOUT, J. T. O espírito da dádiva. Rio de Janeiro: Fundação Getúlio Vargas, 1999.

HIMMELFARB, G. Las "clases andrajosas" y las "clases peligrosas": la idea de la pobreza. Inglaterra a principios de la época industrial. México: Fondo de Cultura Económica, 1988.

LÓPEZ, P.P.; LIMA, R.C.; MATHIEU, G. La intervención con adolescentes y jóvenes en la prevención y promoción de la salud. Esp. Salud Publica, n.5, p.577- 84, 2002.

MALTA, D.C. Buscando novas modelagens em saúde: as contribuições do Projeto Vida e do acolhimento na mudança do processo de trabalho na rede pública de Belo Horizonte, 1993-1996. 2001. Tese (Doutorado) - Faculdade de Medicina Preventiva, Universidade de Campinas, Campinas.

MERHY, E.E. Em busca da qualidade dos serviços de saúde: os serviços de porta aberta para a saúde e o modelo tecnoassistencial em defesa da vida (ou como aproveitar os ruídos do cotidiano dos serviços de saúde e colegiadamente reorganizar o processo de trabalho na busca da qualidade das ações de saúde). In: CECíLIO, L.C.O. (Org.) Inventando a mudança em saúde. São Paulo: Hucitec, 1994. p.116-60.

MERHY, E.E. Em busca do tempo perdido: a micropolítica do trabalho vivo em saúde. In: MERHY, E.E.; ONOCKO, R. (Orgs.) Agir em saúde: um desafio para o público. São Paulo: Hucitec, 1997. p.71.

MATTOS, R.A. Os sentidos da integralidade: algumas reflexões acerca dos valores que merecem ser defendidos In: PINHEIRO, R.; MATTOS, R.A. (Orgs.) Os sentidos da integralidade na atenção e no cuidado à saúde. Rio de Janeiro: IMS-UERJ, 2001. p.39-64.

OLIVEIRA, J.S. Juventude pobre: o desafio da integração. 1999. Tese (Doutorado) - Instituto de Medicina Social, Universidade do Estado do Rio de Janeiro, Rio de Janeiro.

PINHEIRO, R. As práticas do cotidiano na relação oferta e demanda dos serviços de saúde: um campo de estudo e construção da integralidade. In: PINHEIRO, R.; MATTOS, R.A. (Orgs.) Os sentidos da integralidade na atenção e no cuidado à saúde. Rio de Janeiro: IMS-UERJ, 2001. p.65-112.

PINHEIRO, R. Práticas de saúde e integralidade: as experiências inovadoras na incorporação e desenvolvimento de novas tecnologias assistenciais de atenção aos usuários no SUS. In: BRASIL. Ministério da Saúde. Experiências Inovadoras no SUS: relatos de experiências. Brasília, 2002. p.15.

PINHEIRO, R.; MATTOS, R. A. Construção da integralidade: cotidiano, saberes e práticas em saúde. Rio de Janeiro: IMS-UERJ, 2003.

PINHEIRO, R.; MATTOS, R. A. Os sentidos da integralidade na atenção e no cuidado à saúde. Rio de Janeiro: IMS-UERJ, 2001.

PRETECEILLE, E.; VALLADARES, L. A desigualdade entre os pobres - favela, favelas. In: HENRIQUES, R. (Org.) Desigualdade e pobreza no Brasil. Rio de Janeiro: IPEA, 2000, p.459-85.

ROUANET, P. S. A democracia cosmopolita. In: NELSON, C. Folha de São Paulo, São Paulo, 2003. (mimeogr.)

SILVA, R.V.B.; STELET, B.P.; PINHEIRO, R.; GUIZARDI, F.L. Do elo ao laço: O agente comunitário na construção da integralidade em saúde. In PINHEIRO,R.; MATTOS, R. A. (Orgs.) Cuidado: as fronteiras da Integralidade. Rio de Janeiro: IMS-UERJ. HUCITEC: ABRASCO, 2004. p.75-90.

SIMIONATTO, I. O social e o político no pensamento de Gramsci. In: AGGIO, A. (Org.) Gramsci: a vitalidade de um pensamento. São Paulo: UNESP, 1998. p.37-64.

SOUZA, S.P.S. A inserção dos médicos no serviço público de saúde: um olhar focalizado no 
Programa de Saúde da Família. 2001. Dissertação (Mestrado em Saúde Coletiva) - Instituto de Medicina Social, Universidade do Estado do Rio de Janeiro, Rio de Janeiro.

TEXEIRA, R.R. O acolhimento num serviço de saúde entendido como uma rede de conversações. In: PINHEIRO, R.; MATTOS, R. (Orgs.) A construção da integralidade: cotidiano, saberes e práticas em saúde. Rio de Janeiro: IMS-UERJ, 2003. p.89-112.

VIANA, A.L.; DAL POZ, M. A reforma em saúde no Brasil: Programa de Saúde da Família no Brasil. Physis, v.8, n.2, p.17-38, 1998.

VICTORA, C.G.; KNAUTH, D.R.; HASSEN, M.N.A. Pesquisa qualitativa em saúde: uma introdução ao tema. Porto Alegre: Tomo Editorial, 2000.
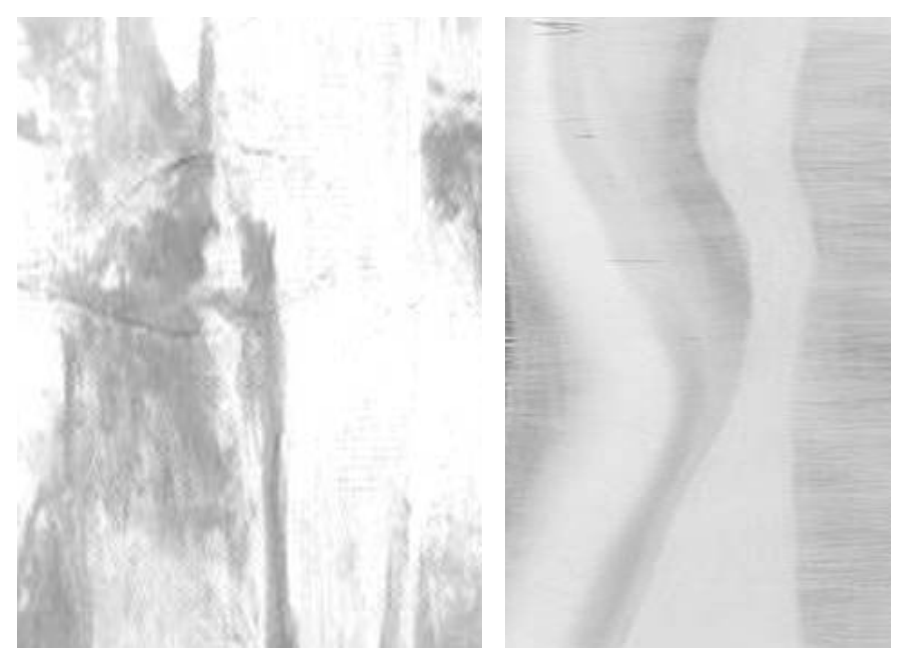

GOMES, M. C. P. A; PINHEIRO, R. Acogida y Vínculo: prácticas de integralidad en la gestión de los cuidados en salud en grandes centros urbanos. Interface - Comunic., Saúde, Educ., v.9, n.17, p.287-301, mar/ago 2005.

La estrategia de Salud de la Familia es la principal propuesta de reorganización del modelo de atención a la salud, apoyada política, institucional y económicamente por el Estado, como alternativa de consolidación de los principios del Sistema único de Salud. La expansión de esa propuesta, en grande centros urbanos, ha encontrado dificultades para su implementación, considerando la complejidad de los contextos sociales, políticos y económicos que atañen a las familias residentes en esos territorios, siendo objeto de discusión de diferentes especialistas en el campo de la Salud Colectiva. Este artículo hace un análisis de los usos y sentidos atribuidos a los términos integralidad, vínculo y acogida, en lo que concierne a la gestión del cuidado en salud, identificando esas estrategias como elementos de las prácticas de salud en programas de atención integral y de la construcción del derecho a la salud como derecho de ciudadanía.

PALABRAS CLAVE: acogida y vínculo; atención integral a la salud; salud de la familia. 


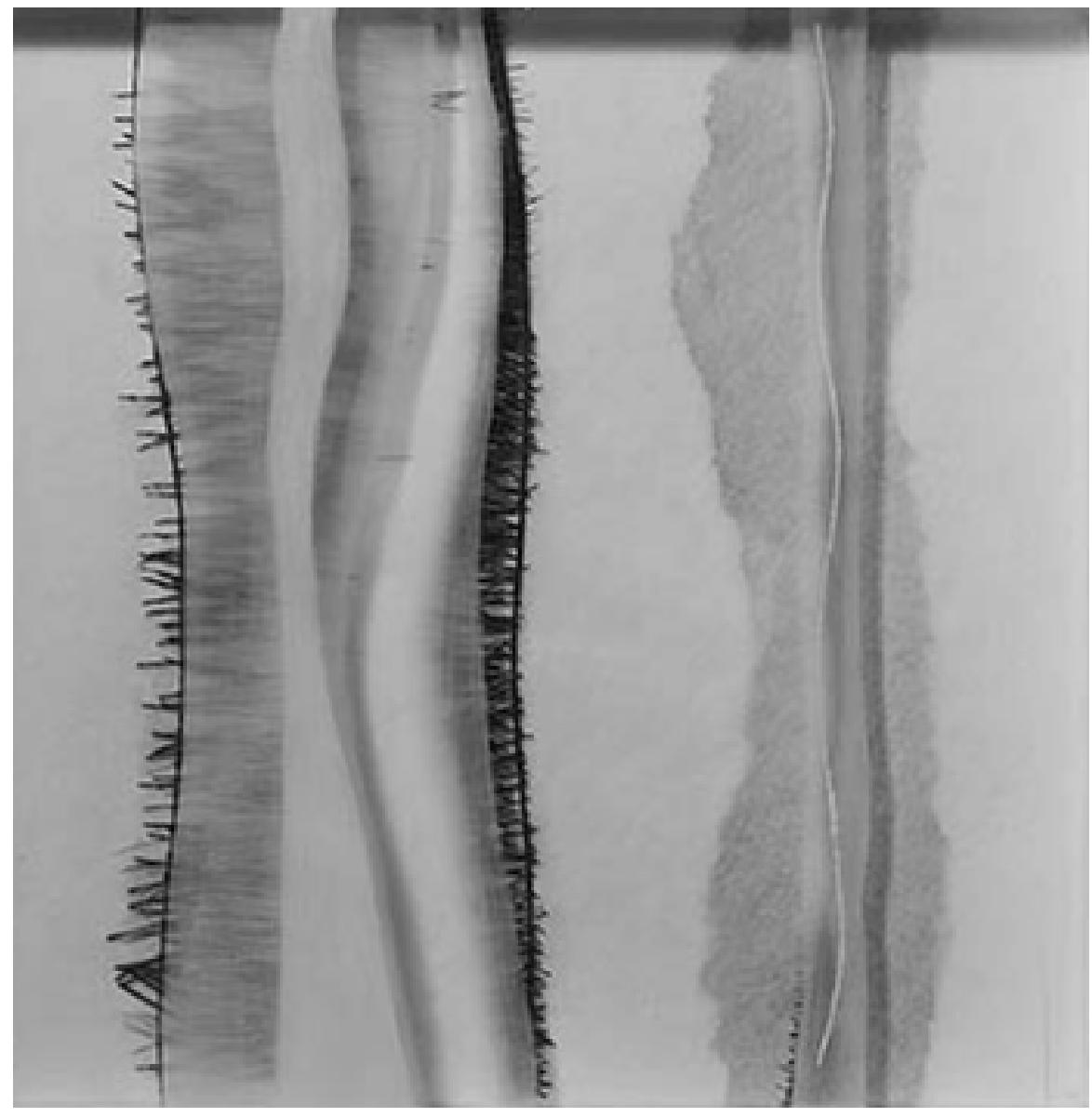

SILVIA MECOZZI, Série Versos Plásticos, 1998 